\title{
COMPREHENSIVE ASSESSMENT OF THE PROPERTIES OF COTTON SINGLE JERSEY KNITTED FABRICS PRODUCED FROM DIFFERENT LYCRA STATES
}

\author{
Amany Khalil ${ }^{1}$, Abdelmonem Fouda ${ }^{2}$, Pavla Těšinová1, Ahmed S. Eldeeb² \\ 1 Textile Evaluation Department, Technical University of Liberec 46117, Liberec, Czechia \\ 2 Textile Engineering Department, Mansoura University, Mansoura 35516, Egypt \\ *Corresponding author. E-mail: engamanysalama@gmail.com
}

\begin{abstract}
:
This research aims to evaluate the properties of cotton single jersey knitted fabrics (SJKF) produced from cotton/ spandex yarns at different Lycra states. So, four different SJKF were produced, namely $100 \%$ cotton, cotton with additional Lycra (full-platted), core, and dual-core-spun (DCS) yarns with the same loop length. The thermal comfort properties, fabric recovery, total hand value (THV), moisture management parameters, and air permeability were measured. The experimental results showed that the use of DCS yarns in the SJKF improves the fabric elastic recovery by $100 \%$. The obtained values of air permeability, THV, and overall moisture management capacity of stretched SJKF are lower than 100\% cotton fabric sample. Thermal absorptivity of core and dual-core samples increased by $27 \%$ and the water vapor permeability decreased by $18 \%$ compared to $100 \%$ cotton fabric sample.
\end{abstract}

\section{Keywords:}

Permanent set, dual-core yarns, thermal properties, overall moisture management capacity, total hand value

\section{Introduction}

Knitted fabrics are characterized by comfort compared to woven fabrics due to their high extensibility, air permeability, and heat retention, but they have low-dimensional stability, especially single jersey knitted fabrics (SJKF), after repeated washing. Therefore, the additional Lycra (elastane) yarns are used to maintain the dimensions of knitted fabrics during use and after repeated stresses.

Recently, the core and dual-core-spun (DCS) yarns are commonly used in stretched denim woven fabrics and there are some researches that evaluated the properties of denim fabrics produced from these yarns. The effect of linear density, twist multiplier, stretch percentage, and applied load on tenacity and elastic performance of cotton/Lycra core-spun denim yarn was investigated [1]. Due to its lower linear density, stretch, and twist multiplier, the cotton/Lycra core-spun yarn has better elastic performance. The weight, size, elasticity, tensile strength, and cost properties of the denim fabrics woven with the dual-core weft yarn with different densities were evaluated [2].

In stretched knitted fabric, the additional Lycra (full- and halfplated) and core-spun yarn are used, and there are many researches that evaluated the geometrical and mechanical properties of these fabrics. Dimensional characteristics of core-spun cotton/Lycra interlock structures with high, medium, and low tightness factors were studied under dry, wet, and full relaxation conditions [3]. The effect of knitting yarn feeding load on the alteration in the mechanical properties of plated plain knitted fabrics was studied [4]. The relation between
Lycra consumption and fabric dimensional and elastic behavior was investigated [5]. The dimensional and physical properties of cotton/spandex SJKF were investigated [6-9] and the effect of extension percentage of bare Lycra yarns during loop formation on the geometrical, physical, and mechanical properties of plain jersey fabrics was studied [10]. According to the previous research, the elastane fibers had a significant effect on the geometrical properties of elastic knitted fabric. As the fabric weight, thickness, and stitch density increased, the air permeability and spirality decreased compared to $100 \%$ cotton fabric.

Limited research discussed the effect of dual-core yarns on the properties of knitted fabrics. The properties of the weft knitted fabrics with different structures (single jersey, rib $1 \times 1$, and full cardigan) produced from core and DCS yarns at different levels of loop length were compared [11]. Results showed that the yarn type had a significant effect on fabric recovery, elasticity, and shrinkage. However, it had insignificant effects on drapability, thermal resistivity, and air permeability. So, more research is required to investigate the properties of stretchable knitted fabric produced from DCS yarns compared to other Lycra states.

This research aims to investigate the geometrical and thermal properties of stretched knitted fabrics produced from cotton yarns with additional Lycra (full-plated), cotton/Lycra corespun, and DCS yarns and then compare the results with the $100 \%$ cotton fabric samples. 


\section{Experimental}

\subsection{Materials}

To investigate the effect of using the Lycra state on the properties of the SJKF, four different SJKF were produced using $100 \%$ cotton, cotton with additional Lycra (full-plated), core-spun, and DCS yarns, at the same loop length $(3 \mathrm{~mm})$ on KEUMYONG KM-3WVP circular knitting machine with Gauge 28, 30-inch diameter, and 90 feeders. The cotton yarn count is $24 \mathrm{Ne}$ (Giza 86, combed, twist multiplier is $3.8 \alpha_{\mathrm{e}}$ ), and the specifications of core and DCS yarns are listed in Table 1. Al fabric samples were washed for three consecutive washing cycles at $60^{\circ} \mathrm{C}$ using laboratory laundering machine. Figure 1 presents the macroscopic images of all SJKF at two extension levels 20 and $40 \%$.

\subsection{Methods}

The fabric recovery was evaluated by calculating the permanent set using a method similar to the ASTM D3107 for denim fabrics [12] but using a constant rate of elongation instead of the constant rate of loading [11]. Knitted samples $\left(30 \times 5 \mathrm{~cm}^{2}\right)$ were subjected to tension by using TENSOLAP tester with a gauge length $20 \mathrm{~cm}$ and applying five levels of extension, namely $15,30,45,60$, and $75 \%$ for 30 min. Later, the length of new samples was measured directly. Then the samples were kept at the standard conditions $\left(20 \pm 2^{\circ} \mathrm{C}\right.$ and $65 \pm 5 \%$ relative humidity) for $2 \mathrm{~h}$ before measuring its new length again. The permanent set before and after relaxation was calculated according to Eq. (1).

Permanent set $(\%)=\left(\frac{L-L_{\mathrm{o}}}{L_{\mathrm{o}}}\right) \times 100$

where $L$ is the sample length after unloading and relaxation, and $L_{\mathrm{o}}$ is the original sample length.

The fabric thickness was measured according to ASTM D1777. The fabric bulk density was calculated using the following formula [13]:

$\operatorname{Bulk}$ density $\left(\mathrm{kg} / \mathrm{m}^{3}\right)=\left(\frac{W\left(\mathrm{~g} / \mathrm{m}^{2}\right)}{t(\mathrm{~mm})}\right)$

Table 1. The knitted yarns characteristics

\begin{tabular}{|c|c|c|}
\hline Yarn types & Dual core & Core \\
\hline Yarn composition & $\begin{array}{c}\text { Cotton } 24.1 \mathrm{Ne}(52.5 \%) / \text { polyester 33.86\%/ } \\
\text { elastane } 13.64 \%(117 \mathrm{dTex})\end{array}$ & $\begin{array}{c}\text { Cotton 24.2 Ne (85.02\%)/elastane } \\
14.98 \%(117 \mathrm{dTex})\end{array}$ \\
\hline Linear density (Ne) & 24.1 & 22.2 \\
\hline Yarn twist (TPI) & 22.58 & 11.5 \\
\hline Irregularity, C.V. (\%) & 10.16 & 5.08 \\
\hline Mean elongation at break (\%) & 10.9 & 4.72 \\
\hline Minimum elongation at break (\%) & 9.97 & 10.07 \\
\hline Mean tenacity (cN/Tex) & 12.06 & 9.47 \\
\hline Minimum tenacity (cN/Tex) & 11.35 & 245.7 \\
\hline Mean breaking force (cN) & 295.4 & \\
\hline
\end{tabular}

\begin{tabular}{|c|c|c|c|c|}
\hline $\begin{array}{c}\text { Type of } \\
\text { yarns }\end{array}$ & Full-plated & Core-spun & Dual core-spun \\
\hline $\begin{array}{c}\text { Fabric } \\
\text { structure } \\
\text { at } 20 \% \\
\text { extension }\end{array}$
\end{tabular}

Figure 1. The macroscopic images of evaluated knitted samples. 
where $W$ is the fabric weight per unit area $\left(\mathrm{g} / \mathrm{m}^{2}\right)$, and $t$ is the fabric thickness $(\mathrm{mm})$.

Thermal comfort properties were measured for all fabric samples. Alambeta instrument was used to measure the dry thermal resistivity according to ISO EN 31092-1994, and relative water vapor permeability (RWVP) was tested by Permetest according to ISO 11092. Air permeability was measured by FX 3300-20 according to EN ISO 9237, and OMMC was measured by M 290 MMT according to ISO 90738. The fabric bursting strength was tested using Tinius Olsen material testing machine 500 according to ASTM D3787-2001. Total hand value (THV) was measured and calculated using Kawabata evaluation system (KES). The statistical analysis of variance (ANOVA) tests was applied using SPSS software to determine the significance levels of the Lycra state on all tested properties.

\section{Results and discussion}

\subsection{Geometrical properties}

The geometrical properties of all samples (thickness, weight, bulk density, and stitch density) are shown in Table 2. The fabric thickness of full-plated samples and samples produced from core and DCS yarns increased by 9,15 , and $11 \%$, respectively, compared to $100 \%$ cotton sample because the additional Lycra leads to stitch overlapping which increases the fabric thickness. The fabric linear density $\left(\mathrm{g} / \mathrm{m}^{2}\right)$ of elastic fabric is higher than $100 \%$ cotton fabric due to the higher stitch density.

\subsection{Permanent set percentage}

Figure 2 shows the relationship between the extension percentage and the permanent set percentage of the four knitted fabrics after relaxation in the standard conditions for $2 \mathrm{~h}$. The $100 \%$ cotton fabric sample had the lowest dimensional stability. The permanent set percentage ranged from 2.5 to $21.5 \%$ and the extension percentage ranged from 15 to $75 \%$, respectively, and this is the main disadvantage of knitted fabrics especially the SJKF. The permanent set of knitted fabrics decreased when the Lycra yarn was added for any Lycra state (full-plated, core, and DCS yarns). The permanent set of full-plated samples was within the acceptable level $(<5 \%)$ but it reached $10 \%$ at the maximum extension $75 \%$. Moreover, it is also noted that the permanent set of dual-core samples dropped to $0 \%$ at four levels of extension of $15,30,45$, and $60 \%$, and recorded only $2 \%$ at $75 \%$. This is may be due to the polyester fibers proportion

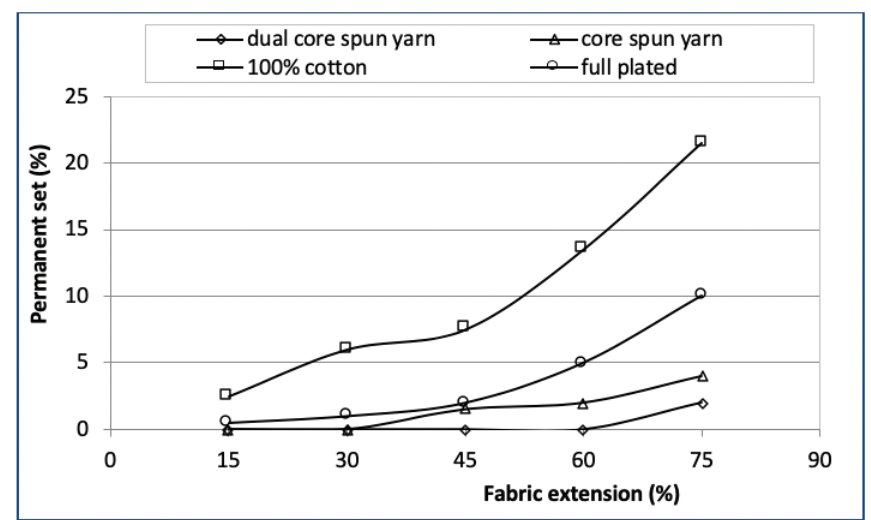

Figure 2. Effect of extension percentage and yarn type on permanent set percentage for single jersey knitted fabrics after relaxation.

in the dual-core yarn construction, which in turn increases the yarn elongation, as previously illustrated in Table 1.

The lowest number of stops was recorded during fabric production with DCS yarns compared to core-spun yarns because of the presence of $33.86 \%$ polyester fibers. However, this ratio of polyester might negatively affect the other knitted fabric properties. The statistical analysis confirmed that the effect of extension percentage and yarn type is significant, as shown in Table 3.

\subsection{Bursting strength}

Figure 3 shows the bursting test for the four different fabrics. The ball reached its maximum distance down but it did not penetrate all samples except the $100 \%$ cotton sample because

Table 3. The results of variance analysis ( $P$ value at $95 \%$ confidence interval)

\begin{tabular}{|c|c|c|}
\hline \multicolumn{2}{|c|}{ Propriety } & Significance \\
\hline \multirow{2}{*}{ Permanent set } & Lycra state & 0.001 \\
\cline { 2 - 3 } & Extension percentage & 0.012 \\
\hline Bursting strength & 0.016 \\
\hline Water vapor permeability & 0.016 \\
\hline \multicolumn{2}{|c|}{ Thermal resistance } & 0.016 \\
\hline Thermal absorptivity & 0.015 \\
\hline Overall moisture management capacity & 0.016 \\
\hline \multicolumn{2}{|c|}{ Air permeability } & 0.015 \\
\hline \multicolumn{2}{|c|}{ Total hand value } & 0.014 \\
\hline
\end{tabular}

Table 2. The dimensional properties of fabric samples

\begin{tabular}{|c|c|c|c|c|}
\hline Yarn types & Fabric thickness $(\mathbf{m m})$ & Fabric weight $\left(\mathbf{g} / \mathbf{m}^{2}\right)$ & Bulk density $\left(\mathbf{k g} / \mathbf{m}^{3}\right)$ & Stitch density $\left(\mathbf{c m} \mathbf{~}^{-2}\right)$ \\
\hline Cotton $100 \%$ & 0.89 & 197.6 & 202.7 & 258 \\
\hline Full-plated & 0.97 & 297.3 & 299.6 & 378 \\
\hline Core spun & 1.08 & 401.1 & 350 & 530 \\
\hline Dual core spun & 0.99 & 385.1 & 376 & 502 \\
\hline
\end{tabular}


of the high extensibility of Lycra. All samples had a good resistance to the bursting strength, but the stretched knitted fabric had a higher extension compared to $100 \%$ cotton samples. The produced samples from core-spun and DCS yarns had the highest elongation at the same strength which gives high extensibility and comfort. This may be due to the Lycra existence in the yarn core.

\subsection{Water vapor permeability}

Water vapor permeability is the ability to transmit vapor out of the body [14]. Figure 4 illustrates the RWVP of all samples. It is noticed that the $100 \%$ cotton sample had the highest RWVP $(65 \%)$ than the full-plated samples (53\%) because of hydrophilic property of cotton fibers compared to Lycra and polyester fibers (moisture regain values are $8.5,0.4$, and $0.1 \%$ for cotton, polyester, and Lycra, respectively), and because they had the lowest stitch density as listed in Table 2. So, there are higher pore sizes that enable the water vapor to transmit compared to the samples produced from core-spun and DCS yarns. Therefore, if these fabrics (produced from core and DCS yarns) are used for underwear or summer t-shirts, it might give a discomfort feeling. This is a negative impact, and the statistical analysis showed that the Lycra state has a significant effect on the RWVP.

\subsection{Thermal resistance and thermal absorptivity}

Due to increase in the thickness of the produced samples by the core-spun yarn, as illustrated in Table 2, the thermal resistance increased as shown in Figure 5 according to Eq. (3).

$$
\boldsymbol{R}=\left(\frac{\boldsymbol{t}}{\boldsymbol{\lambda}}\right)
$$

where $R$ is the thermal resistance $\left(K \cdot \mathrm{m}^{2} . \mathrm{W}^{-1}\right), \lambda$ is the thermal conductivity $\left(\mathrm{W} \cdot \mathrm{m}^{-1} \cdot \mathrm{K}^{-1}\right)$, and $t$ is the fabric thickness $(\mathrm{m})$.

If the thermal resistance of clothing is low, heat energy will tend to gradually decrease, giving rise to a cool feeling [15]. So, if these fabrics are used as winter clothes, they will retain the temperature of the human body and give a warm feeling due to their higher thermal resistance [16].

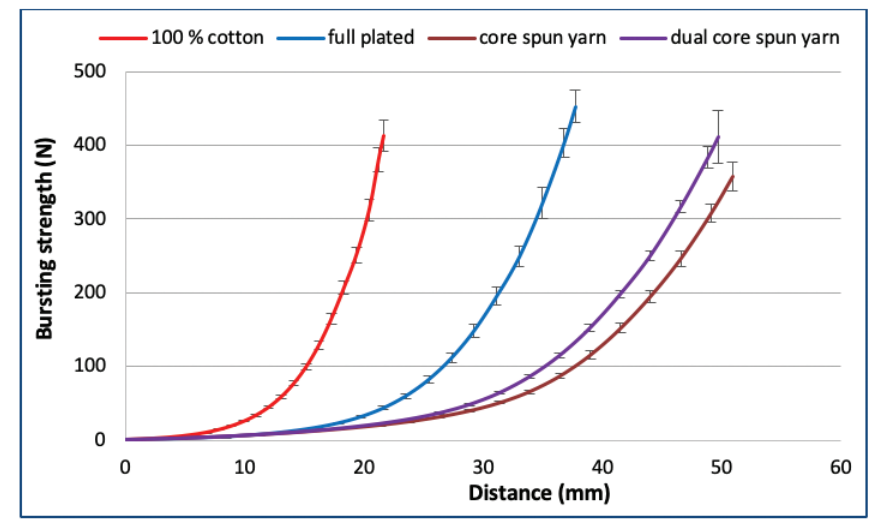

Figure 3. The relation between bursting strength and displacement for single jersey knitted fabrics.
Thermal absorptivity is the objective measurement of the warm-cool feeling of fabrics at the first touch [17]. When the thermal absorptivity increases, it gives a cool feeling. Figure 6 displays the thermal absorptivity of the four SJKF. The thermal absorptivity increased by $20 \%$ for the full-plated samples and $27 \%$ for the samples produced from core and DCS yarns compared to $100 \%$ cotton sample. This may be because the cotton samples had the lowest stitch density, as shown in Table 3, according to Eq. (4) [18].

$$
b=(\lambda \rho c)^{1 / 2}
$$

where $b$ is the thermal absorptivity $\left(\mathrm{W} \cdot \mathrm{S}^{1 / 2} \cdot \mathrm{m}^{-2} \cdot \mathrm{K}^{-1}\right), \lambda$ is the thermal conductivity, $\rho$ is the fabric density $\left(\mathrm{kg} / \mathrm{m}^{3}\right)$, and $c$ is the specific heat capacity $\left(\mathrm{J} \cdot \mathrm{kg}^{-1} \cdot \mathrm{K}^{-1}\right)$.

So, these fabrics will give cool feeling more than $100 \%$ cotton fabric. The statistical analysis confirmed that the effect of Lycra state on thermal resistance and absorptivity is significant.

\subsection{Air permeability}

Figure 7 shows the air permeability of fabric samples with different Lycra state. The air permeability reduced by $96 \%$ in case of the produced samples from core-spun yarn and by $80 \%$ in the full-platted samples compared to $100 \%$ cotton sample due to the higher fabric density and stitch density. So,

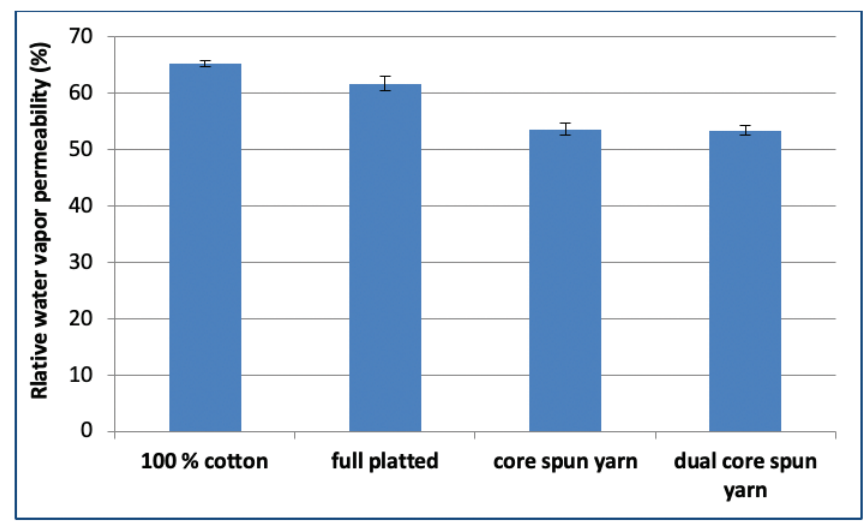

Figure 4. Effect of Lycra state on relative water vapor permeability percentage for single jersey knitted fabrics.

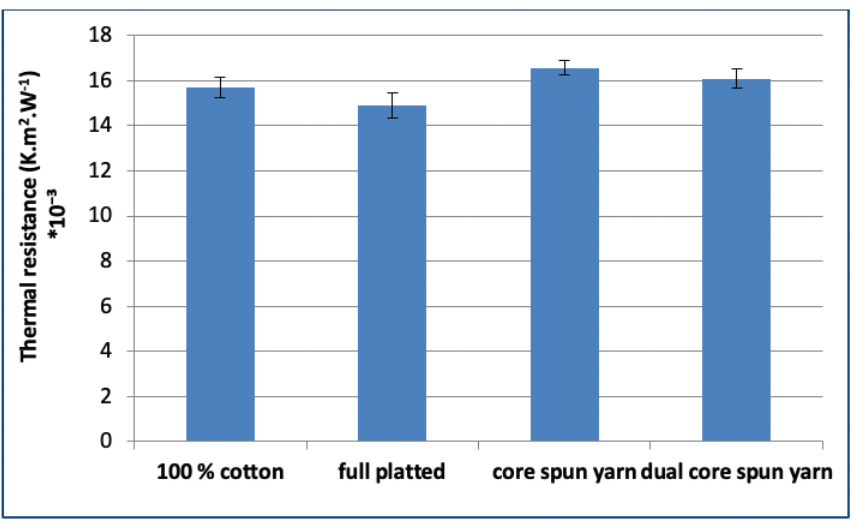

Figure 5. Effect of Lycra state on thermal resistance of single jersey knitted fabrics. 


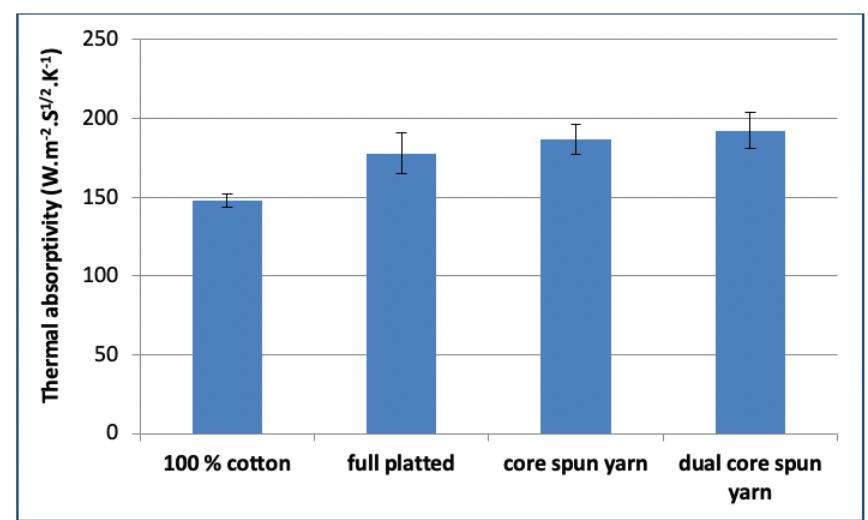

Figure 6. Effect of Lycra state on thermal absorptivity of single jersey knitted fabrics.

the spacing and pores between the loops (stitches) and each other decreased. The statistical analysis showed that the effect of Lycra state on the air permeability is significant.

\subsection{Moisture management parameters}

The results of moisture management parameters were summarized in Table 4. Figure 8 displays the accumulative one-way transport capacity (OWTC) of samples with different Lycra states. The OWTC is defined as the difference in the accumulative moisture content between the top and bottom layers of the fabric in the unit of testing time period [19]. The full-plated and $100 \%$ cotton samples had the largest OWTC, and this may be due to decrease in the stitch density which achieves more possibility of water penetration in voids and the higher cotton fibers volume fraction compared to the produced samples from core and DCS yarns, so it absorbs much water. Therefore, the fabric can transmit the sweat from the body surface to the fabric surface quickly. The $100 \%$ cotton sample had the highest OWTC than the full-plated sample. The OWTC of the sample produced from DCS yarns is higher than the sample produced from core-spun yarn. So, the sweat will transfer much faster in case of the sample produced from DCS yarns compared to core-spun yarns.

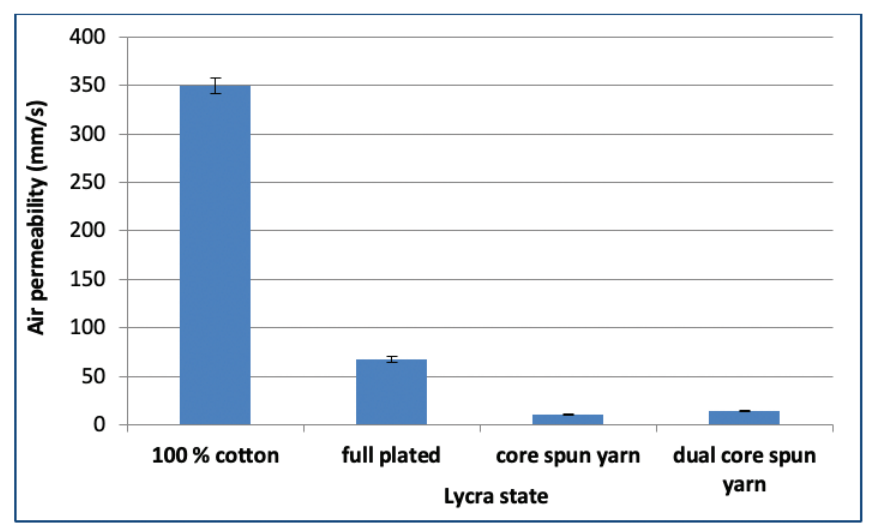

Figure 7. Effect of Lycra state on air permeability for single jersey knitted fabrics.

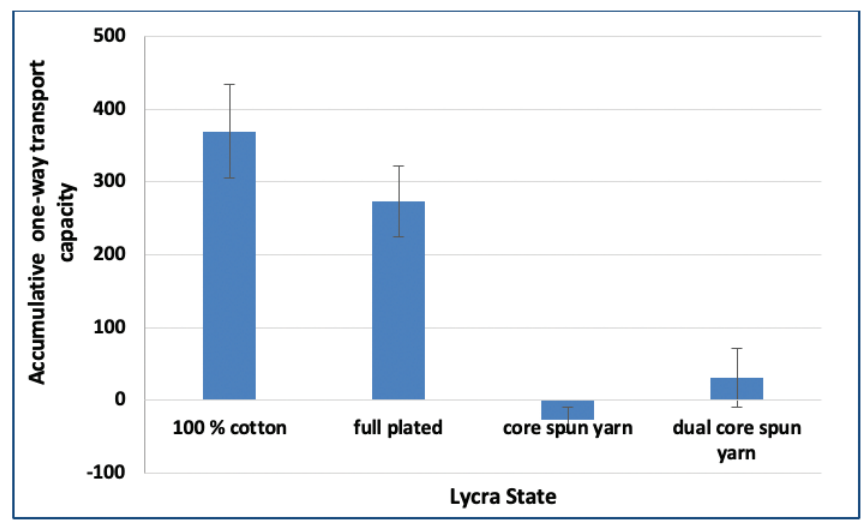

Figure 8. Effect of Lycra state on one-way transport capacity single jersey knitted fabrics.

The overall moisture management capacity (OMMC) is a term that indicates how the fabric is capable of managing the moisture transfer. It can be measured and calculated as follows [19-21]:

$$
\mathrm{OMMC}=C_{1} \mathrm{BAR}+C_{2} \mathrm{OWTC}+C_{3} \mathrm{BSS}
$$

Table 4. Fabric moisture management parameters

\begin{tabular}{|c|c|c|c|c|c|}
\hline Parameters & Symbols & $\begin{array}{c}100 \% \text { cotton } \\
\text { yarn }\end{array}$ & $\begin{array}{c}\text { Full-plated } \\
\text { yarn }\end{array}$ & $\begin{array}{c}\text { Core-spun } \\
\text { yarn }\end{array}$ & $\begin{array}{c}\text { Dual-core-spun } \\
\text { yarn }\end{array}$ \\
\hline Wetting time top (s) & WTT & 15.99 & 15.28 & 6.44 & 8.71 \\
\hline Wetting time bottom (s) & WTB & 6.31 & 9.86 & 17.49 & 16.68 \\
\hline Top absorption rate $(\% / s)$ & TAR & 39.29 & 33.41 & 38.88 & 42.29 \\
\hline Bottom absorption rate (\%/s) & BAR & 83.60 & 87.60 & 31.32 & 34.41 \\
\hline Top max wetted radius $(\mathrm{mm})$ & MWRT & 17 & 14 & 16 & 13.75 \\
\hline Bottom max wetted radius $(\mathrm{mm})$ & MWRB & 18 & 16 & 17 & 16.25 \\
\hline Top spreading speed $(\mathrm{mm} / \mathrm{s})$ & TSS & 0.99 & 1.12 & 1.11 & 0.86 \\
\hline Bottom spreading speed $(\mathrm{mm} / \mathrm{s})$ & BSS & 1.43 & 1.27 & 0.81 & 0.72 \\
\hline Accumulative one-way transport capacity & OWTC & 382.89 & 276.67 & -63.77 & 30.10 \\
\hline Overall moisture management capacity & OMMC & 0.655 & 0.597 & 0.086 & 0.160 \\
\hline
\end{tabular}


where $C_{1}=0.25, C_{2}=0.5$, and $C_{3}=0.25$ are the weights of bottom absorption rate (BAR), OWTC, and bottom spreading speed (BSS), respectively.

It is known that the higher the OMMC, the higher the overall moisture management ability of that fabric. Figure 9 displays the effect of Lycra state on the OMMC. It can be concluded that OMMC of the $100 \%$ cotton and full-plated samples are higher than the produced samples from core and DCS yarns because they had higher values of BAR, OWTC, and BSS due to the higher water absorption of cotton fibers. So, the ability of managing the moisture transfer of the $100 \%$ cotton and fullplated fabrics is better than the produced samples from core and DCS yarns. The effect of the Lycra state on the overall moisture management is significant as demonstrated in the statistical analysis (see Table 3).

\subsection{Total hand value}

The primary HV and THV of all samples were determined by KES where 16 properties were measured. The system uses multivariate regression to relate the subjective assessment results completed by the Japanese experts to the objectively measured data on the KES-F instruments and to formulate the equations for HV calculation. The primary hand properties depend on the end use of the fabric. Those samples are used as
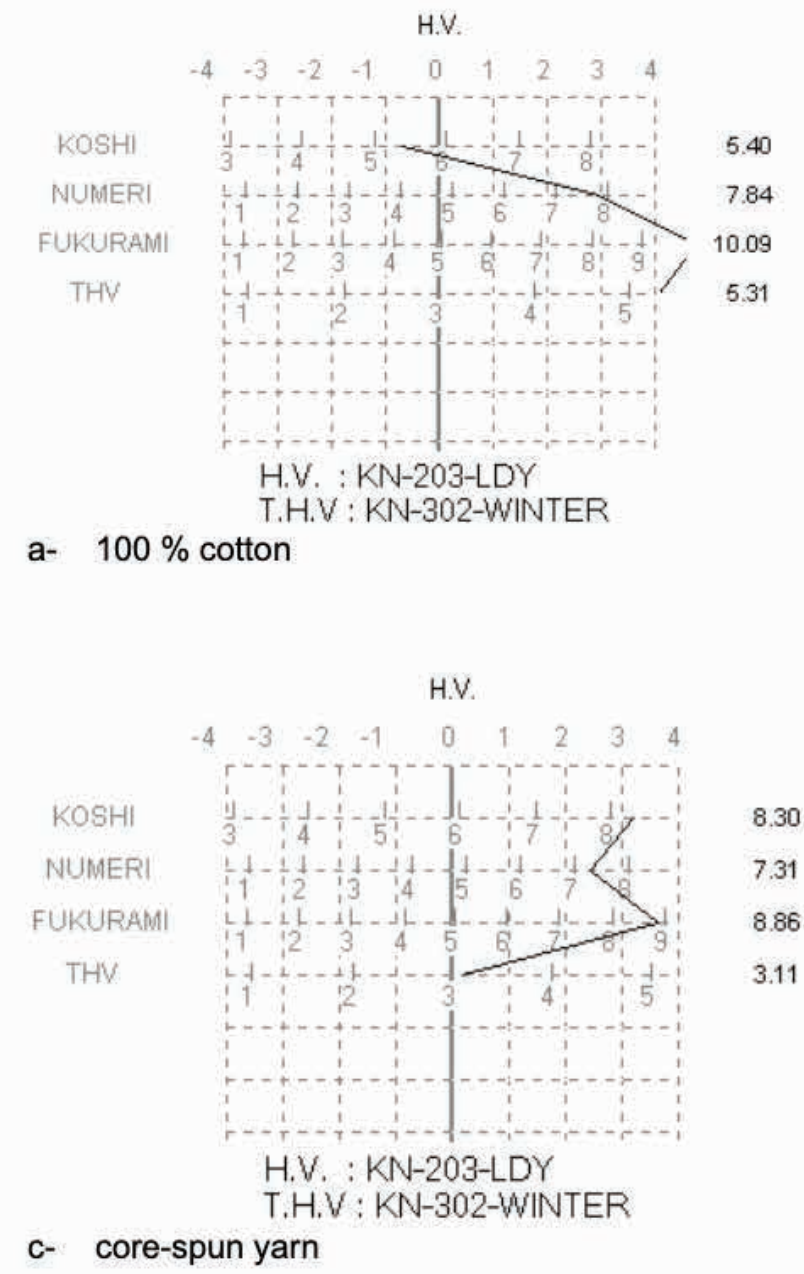

winter lady thin wear, so the primary hand properties are Koshi (stiffness), Numeri (smoothness), and Fukurami (fullness and softness). Primary HV is ranked from 0 to 10 corresponding to the intensity of feeling whereas the large number corresponds to the strong feeling of hand. THV was standardized using a scale of $0-5$ from unacceptable to excellent [22]. Figure 10 shows the HV and THV of different samples of Lycra state. THV of fabric sample produced from $100 \%$ cotton yarn was the highest. This value decreased with sample produced from additional Lycra, core-spun, and DCS yarns by 17, 38,

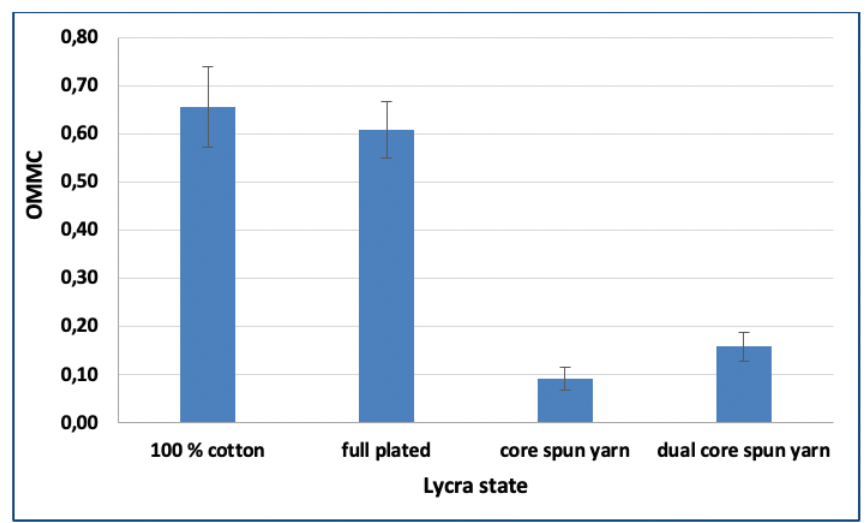

Figure 9. Effect of Lycra state on overall moisture management capacity for single jersey knitted fabrics.
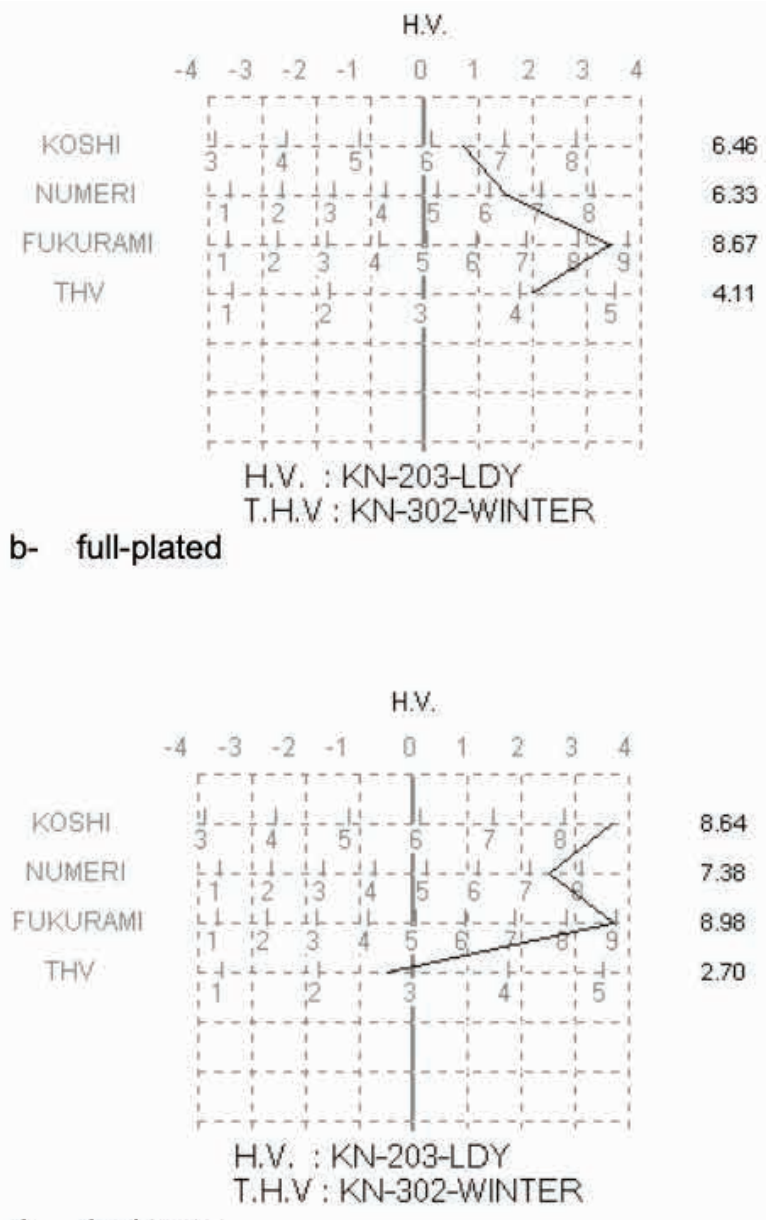

d- dual-core

Figure 10. Primary hand value and total hand value of different Lycra state, 
and $45 \%$, respectively. This is may be due to the structural properties of each yarn.

\section{Conclusions}

Four different SJKF (100\% cotton, cotton with full-platted Lycra, core, and DCS yarns) were produced to estimate the properties of cotton SJKF produced by different Lycra states. The thermal comfort properties, fabric recovery, THV, moisture management parameters, and air permeability were measured.

The results showed that the use of DCS yarns in the SJKF improves the fabric recovery by $100 \%$ at various tensile levels compared to sample produced from $100 \%$ cotton yarn, and by $55 \%$ compared to the full-plated fabric sample. The produced samples from core-spun and DCS yarns had the highest elongation at the same strength which gives extensibility and comfort. Thermal absorptivity of core and DCS samples increased by $27 \%$ and the water vapor permeability decreased by $18 \%$ compared to $100 \%$ cotton sample. Overall moisture management of dual sample decreased by $75 \%$ and air permeability dropped to $96 \%$ compared to $100 \%$ cotton samples, which gives discomfort feeling. The THV of dual sample reduced to $34 \%$ compared to full-plated fabric samples.

In general, the production process of knitted fabrics produced from core and DCS yarns is much easier than additional Lycra with cotton yarns in production because special Lycra feeders are needed. Also, the use of DCS yarns is better than the corespun yarns, where the number of breaks and stops are lower, so the quality and productivity could improve.

\section{Acknowledgment}

This work is supported under Student Grant Scheme (SGS 21316) by Technical University of Liberec, Czech Republic.

\section{References}

[1] Sinha, S. K., Bansal, P., Maity, S. (2017). Tensile and elastic performance of cotton/lycra core spun denim yarn. Journal of the Institution of Engineers (India): Series E, 98(1), 71-78.

[2] Ertaş, O. G., Zervent Ünal, B., Çelik, N. (2016). Analyzing the effect of the elastane-containing dual-core weft yarn density on the denim fabric performance properties. Journal of The Textile Institute, 107(1), 116-126.

[3] Herath, C. N., Kang, B. C., Jeon, H. Y. (2007). Dimensional stability of cotton-spandex interlock structures under relaxation. Fibers and Polymers, 8(1), 105.

[4] Fatkić, E., Geršak, J., Ujević, D. (2011). Influence of knitting parameters on the mechanical properties of plain jersey weft knitted fabrics. Fibres \& Textiles in Eastern Europe, 19(5), 88.
[5] Abdessalem, S. B., Abdelkader, Y. B., Mokhtar, S., Elmarzougui, S. (2009). Influence of elastane consumption on plated plain knitted fabric characteristics. Journal of Engineered Fibers and Fabrics, 4(4), 155892500900400411.

[6] Marmarali, A. B. (2003). Dimensional and physical properties of cotton/spandex single jersey fabrics. Textile Research Journal, 73(1), 11-14.

[7] Sitotaw, D. B. (2018). Dimensional characteristics of knitted fabrics made from $100 \%$ cotton and cotton/elastane yarns. Journal of Engineering, 2018(1), 1-9.

[8] Prakash, C. (2018). Investigation on geometric and dimensional properties of cotton sheath elastomeric core spun yarn single jersey and popcorn jersey fabric structures. Latest Trends in Textile and Fashion Designing, 2(1), 136-142.

[9] Aboalasaad, A. R., Sirková, B. K., Tešinová, P., Khalil, A. (2019). Guidelines for measuring thermal resistance on thermal Foot Manikin. Materials Today: Proceedings. Published online 26 November 2019. https://doi. org/10.1016/j.matpr.2019.11.068

[10] Sadek, R., El-Hossini, A. M., Eldeeb, A. S., Yassen, A. A. (2012). Effect of lycra extension percent on single jersey knitted fabric properties. Journal of Engineered Fibers and Fabrics, 7(2), 155892501200700203.

[11] Fouda, A., Eldeeb, A. S. (2018). Properties of weft knitted fabrics made from dual core-spun yarns. 8th International Istanbul Textile Conference - Evolution Technical Textile (ETT2018), April 14-16, 2018, İstanbul, Turkey, 2018, pp. 1-7.

[12] ASTM D3107: 2004. (2004). Stretch properties of woven fabrics. Modified 2004, pp. 1-3.

[13] Salama, A. A., El-Deeb, A. S., El-Shahat, I. M. (2015). Evaluation of bed cover properties produced from double fabric based on honeycomb. Journal of Textiles, 2015, 7.

[14] Raja, D., Prakash, C., Gunasekaran, G., Koushik, C. V. (2015). A study on thermal properties of single-jersey knitted fabrics produced from ring and compact folded yarns. The Journal of The Textile Institute, 106(4), 359365.

[15] Ramakrishnan, G., Umapathy, P., Prakash, C. (2015). Comfort properties of bamboo/cotton blended knitted fabrics produced from rotor spun yarns. The Journal of The Textile Institute, 106(12), 1371-1376.

[16] Aboalasaad, A. R., Skenderi, Z., Brigita, K. S., Khalil, A. A. (2019). Analysis of factors affecting thermal comfort properties of woven compression bandages. Autex Research Journal. doi: 10.2478/aut-2019-0028.

[17] Oğlakcioğlu, N., Marmarali, A. (2007). Thermal comfort properties of some knitted structures. Fibres \& Textiles in Eastern Europe, 15(5-6), 64-65.

[18] Hes, L., De Araujo, M., Djulay, V. V. (1996). Effect of mutual bonding of textile layers on thermal insulation and thermal contact properties of fabric assemblies. Textile Research Journal, 66(4), 245-250.

[19] Hu, J., Li, Y., Yeung, K. W., Wong, A. S., Xu, W. (2005). Moisture management tester: a method to characterize fabric liquid moisture management properties. Textile Research Journal, 75(1), 57-62. 
[20] Supuren, G., Oglakcioglu, N., Ozdil, N., Marmarali, A. (2011). Moisture management and thermal absorptivity properties of double-face knitted fabrics. Textile Research Journal, 81(13), 1320-1330.

[21] Achour, N. S., Hamdaoui, M., Nasrallah, S. B., Perwuelz, A. (2015). Investigation of moisture management properties of cotton and blended knitted fabrics. International Journal of Chemical, Molecular, Nuclear, Materials and Metallurgical Engineering, 9(7), 879-883.

[22] Behera, B. K., Hari, P. K. (1994). Fabric quality evaluation by objective measurement. Indian Journal of Fibre \& Textile Research, 19, 168-171. 